Article

\title{
Characterization and Analysis of Metal Adhesion to Parylene Polymer Substrate Using Scotch Tape Test for Peripheral Neural Probe
}

\author{
Seonho Seok ${ }^{1,+}{ }^{\text {, HyungDal Park }}{ }^{2,+}+\mathbb{D}$ and Jinseok Kim ${ }^{2, *}$ \\ 1 Center for Nanoscience and Nanotechnology (C2N), University-Paris-Saclay, Orsay 91400, France; \\ seonho.seok@u-psud.fr \\ 2 Center for Bionics, Korea Institute of Science and Technology (KIST), Seongbuk-gu, Seoul 02792, Korea; \\ hyungdal@kist.re.kr \\ * Correspondence: jinseok@kist.re.kr \\ + Both authors are equally-contributed to this manuscript.
}

Received: 3 June 2020; Accepted: 19 June 2020; Published: 22 June 2020

\begin{abstract}
This paper presents measurement and FEM (Finite Element Method) analysis of metal adhesion force to a parylene substrate for implantable neural probe. A test device composed of $300 \mathrm{~nm}$-thick gold and $30 \mathrm{~nm}$-thick titanium metal electrodes on top of parylene substrate was prepared. The metal electrodes suffer from delamination during wet metal patterning process; thus, $\mathrm{CF}_{4}$ plasma treatment was applied to the parylene substrate before metal deposition. The two thin film metal layers were deposited by e-beam evaporation process. Metal electrodes had $200 \mu \mathrm{m}$ in width, $300 \mu \mathrm{m}$ spacing between the metal lines, and $5 \mathrm{~mm}$ length as the neural probe. Adhesion force of the metal lines to parylene substrate was measured with scotch tape test. Angle between the scotch tape and the test device substrate changed from $60^{\circ}$ to $90^{\circ}$ during characterization. Force exerted the scotch tape was recorded as the function of displacement of the scotch tape. It was found that a peak was created in measured force-displacement curve due to metal delamination. Metal adhesion was estimated $1.3 \mathrm{~J} / \mathrm{m}^{2}$ by referring to the force peak and metal width at the force-displacement curve. Besides, the scotch tape test was simulated to comprehend delamination behavior of the test through FEM modeling.
\end{abstract}

Keywords: adhesion; thin film metal; parylene; neural probe; scotch tape test; FEM

\section{Introduction}

Many research efforts have been made to develop and improve of the prosthetic hands and arms for the amputees, and, in recent years, much progress has been observed in the development of life-like robotic hands and the means of controlling them with greater degree of freedom. For this purpose, micro-electro-mechanical systems (MEMS) technologies have been used to fabricate neural interface probes [1-6]. However, existing MEMS-based neural electrodes would have a limitation on the neural interface due to its material characteristics. Thus, flexible neural electrodes have been recently proposed to minimize mechanical mismatch between the electrode and tissue after the electrode's implantation for a stable long-term recording and stimulation. To this sense, peripheral neural interface (PNI) devices have appeared to retrieve and send neural signals directly from and to the residual or existing peripheral nerves in this field [7]. Recently, thin film flexible polymeric devices are being used for measuring nerve impulse from the central or peripheral nerve systems [8-13]. Such flexible polymeric devices tend to be designed several $\mu \mathrm{m}$ in thickness and a few $\mathrm{mm}$ in length due to its nature of interfacing with neurons in human body. Consequently, metal electrodes on such a thin and long polymeric substrate have constraints to be at best several hundred nanometers. Thus, metallization 
technology frequently used is PVD (Physical Vapor Deposition), such as evaporation or sputtering. The PVD metal layers are formed into long and thin metal lines through wet-etch or lift-off technique. Although thin-film polymeric devices are flexible and biocompatible, they are prone to delamination and carry concerns about their mechanical robustness [14]. A nanopillar array created by plasma etching could be used to enhance adhesion among different materials in the parylene-metal-parylene system [15]. ALD (Atomic layer deposition) Al2O3 combined with the silane adhesion promoter A-174 would increase adhesion force between two parylene films [14]. Parylene material has been shown that mechanical properties can be maintained after stored in PBS (Phosphate Buffered Saline) solution up to 12 months [16]. Therefore, mechanical or chemical treatments of the interface between polymer substrate and metal film is frequently required [17]. However, concrete characterization of metal adhesion to parylene substrate dedicated to neural probe is still insufficient. Scotch tape test has been frequently used to estimate adhesion force of metal layers to polymer substrates [18-20]. Tape is often used to overcome the adhesion challenges in what's commonly known as the "tape test," which is a variation of ASTM (American Society for Testing and Materials) D-3359 [21].

In this paper, metal adhesion to parylene substrate has been characterized by using scotch-tape test and it has been analyzed based on Finite Element Method (FEM) modeling. Sample preparation for adhesion test is presented in Section 2. Scotch tape test results are explained in Section 3. FEM modeling and simulation of the scotch tape test is depicted in Section 4. Finally, conclusion will be made in Section 5 .

\section{Test Sample Preparation for Metal Parylene Adhesion Test}

Figure 1 shows the schematic of test pattern; it has length of $50 \mathrm{~mm}$ and width of $5 \mathrm{~mm}$. It consists of 6 metal lines; each metal line has $200 \mu \mathrm{m}$ in width and is spaced at $300 \mu \mathrm{m}$ as is the design of multi-channel neural probe. Test pattern fabrication process is shown in Figure 2; (a) A parylene (parylene-C) layer having $5 \mu \mathrm{m}$ in thickness was deposited in a 4-inch Si wafer using by commercial parylene coater system (VPC-500, Paco Engineering, Incheon, Korea). The monomer was deposited on the surface of the silicon wafer at a vapor phase condition with $0.8 \mu \mathrm{m} / \mathrm{min}$, and deposition temperature was $20^{\circ} \mathrm{C}$. (b) Before metal layers deposition, the parylene surface was etched with $\mathrm{CF}_{4}$ gas (process conditions; ( $25 \mathrm{mTorr}, 20 \mathrm{sccm}, 1.5 \mathrm{~min})$ ) without $\mathrm{O}_{2}$ in order to increase surface roughness reducing the hydrophobicity, as shown in Figure 3. Note that $\mathrm{O}_{2}$ was not used for surface modification since the parylene is susceptible to be surface oxidation causing degradation of mechanical properties of the polymer neural probe. Moreover, the nanopillar structures on parylene substrate was efficiently built with $\mathrm{CF}_{4}$ gas rather than $\mathrm{O}_{2}$ gas, as shown in Figure 3b,c. Besides, there have been two major methods to improve interfacial adhesion between parylene and metal layer: chemical treatment or mechanical surface modification with RIE (Reactive Ion Etching) etch (Plasma-therm 790 MF, Plasma-Therm, Saint Petersburg, FL, USA). Concerning the test sample used in our study, parylene was already deposited on a silicon substrate; thus, chemical treatment may have changed the properties of parylene substrate itself, as well as the interface on which the metal was deposited. Furthermore, RIE etch have shown better performance compared with conventional A-174 saline chemical treatment [15]. Therefore, we modified the parylene surface with $\mathrm{CF}_{4}$ plasma etch to make a nanopillared surface, increasing the interfacial energy. The effectiveness of the nanopillared parylene surface was confirmed during metal patterning step. Titanium $(30 \mathrm{~nm})$ and gold $(300 \mathrm{~nm})$ were sequentially deposited with using by E-beam evaporator (ei5, ULVAC, Methuen MA, USA) on the parylene substrate without rupture of vacuum. (c) Photoresist (AZ GXR 601 (46cp), Merck, Kenilworth, NJ, USA) was patterned as a metal etch mask. The process conditions are summarized in Table 1. (d) Gold was first etched with Au etchant (Gold ETCH TFA, Transene Company, Danvers, MA, USA) for 5 min, and then titanium is etched with BOE (Buffered Oxide Etchant) solution (Buffered oxide etch 6:1, VWR International, Radnor, PA, USA) for $10 \mathrm{~s}$. After metal patterning, PR mask was removed with acetone. Etch time was $60 \mathrm{~s}$. 


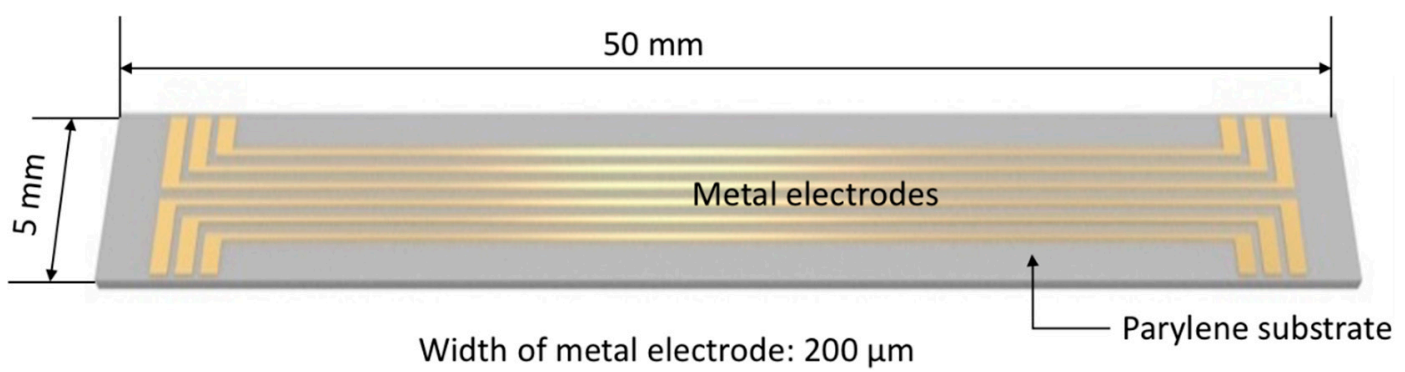

Spacing between metal electrodes: $300 \mu \mathrm{m}$

Figure 1. Design of test pattern.

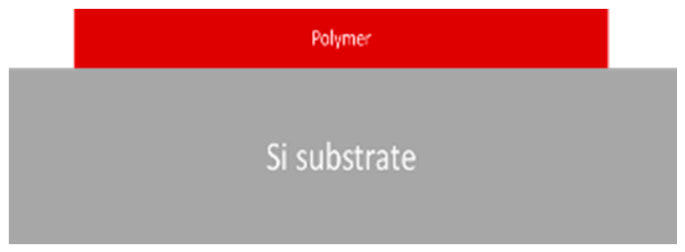

(a) Parylene depositon

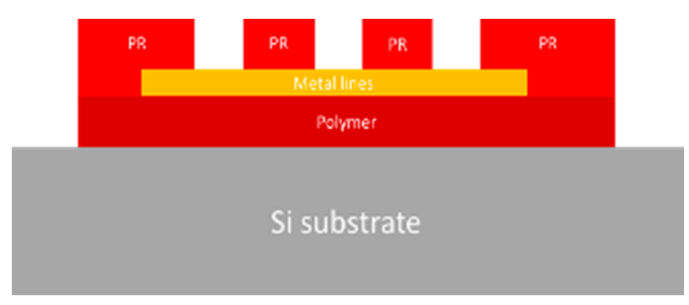

(c) PR mask patterning

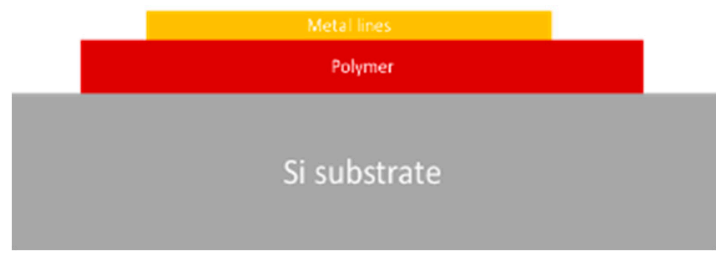

(b) Au/Ti deposition

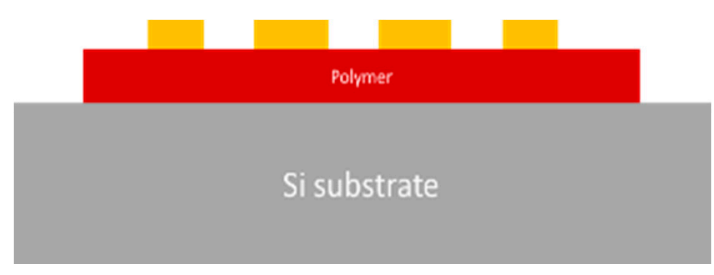

(d) Wet-etch of metals

Figure 2. Test sample fabrication process.

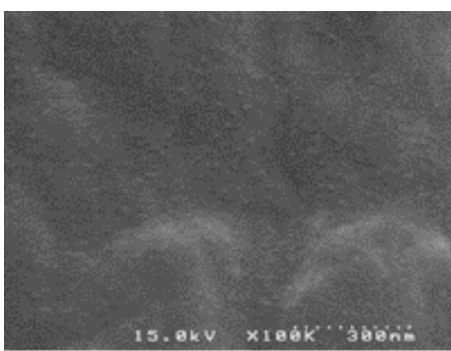

(a) Untreated

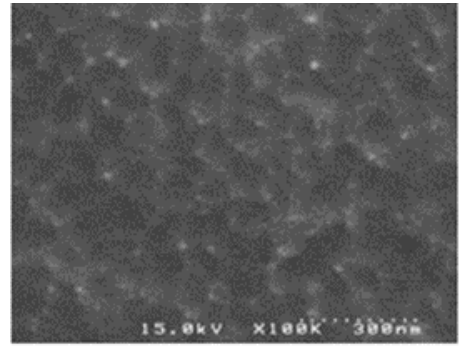

(b) $\mathrm{O}_{2}$ treatment

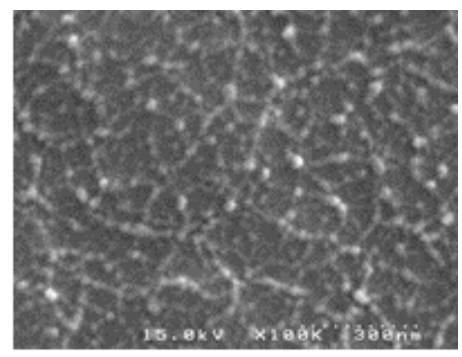

(c) $\mathrm{CF}_{4}$ treatment

Figure 3. Parylene surface modification. 
Table 1. Photoresist etch mask process conditions.

\begin{tabular}{cc}
\hline Step & Conditions \\
\hline PR coating & $10 \mathrm{~s} @ 1500 \mathrm{rpm}$ \\
Soft bake & $60 \mathrm{~s} @ 95^{\circ} \mathrm{C}$ \\
Exposure & $10 \mathrm{~s} @ 10 \mathrm{~mW}$ \\
Develop & $10 \mathrm{~s} @$ developer \\
Post exposure bake & $30 \mathrm{~s} @ 110^{\circ} \mathrm{C}$ \\
Thickness & $1.2 \mu \mathrm{m}$ \\
\hline
\end{tabular}

Resultant test samples on 4-inch silicon wafer is shown in Figure 4. All of metal lines were successfully implemented on the parylene substrate without any delamination during etching process. Note that the metal lines were fully delaminated from the parylene substrate during metal wet-etch step.

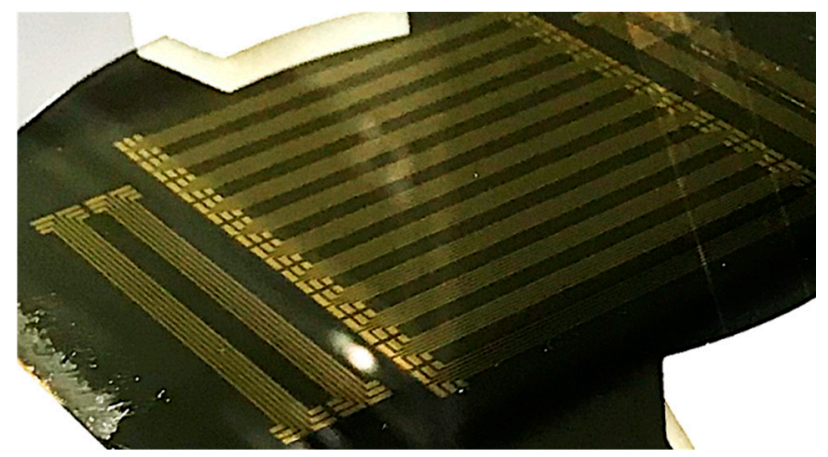

Figure 4. Test samples fabricated on 4-inch silicon substrate.

\section{Scotch Tape Test for Metal Adhesion to Parylene Substrate}

The prepared test samples underwent the scotch tape test to evaluate adhesion strength of the metal electrodes to the parylene substrate. The machine used for the scotch tape test was Shimadzu EZ-S machine (Shimadzu, Kyoto, Japan) dedicated for tensile testing. Figure 5 shows a photo of scotch tape attached on the test sample and schematics of the scotch tape test, respectively. The scotch tape is $3 \mathrm{M}$ transparent tape 550. It has thickness of $50 \mu \mathrm{m}$ and $12 \mathrm{~mm}$ width, and it provides adhesion to steel of $1.8 \mathrm{~N} / \mathrm{cm}$ (or $0.18 \mathrm{~N} / \mathrm{mm}$ ).

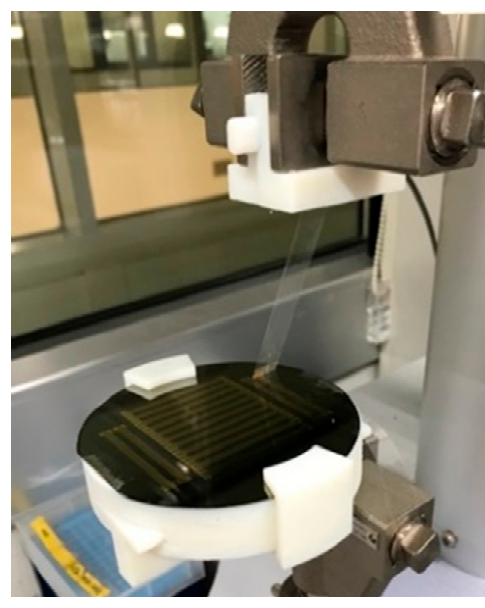

(a) test setup

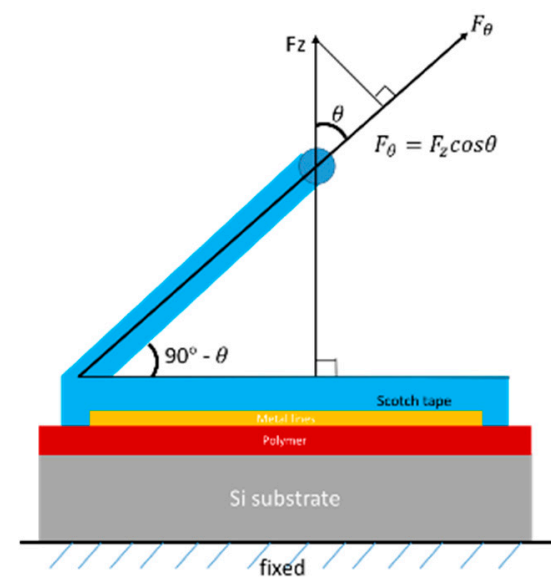

(b) scotch tape test schematic

Figure 5. Scotch tape test for metal adhesion to parylene substrates. 
Referring to Figure 5b, the scotch tape test was carried out in the following way; the machine applies stroke (unit: $\mathrm{mm} / \mathrm{min}$ ) into one end of the scotch tape, and then it measures force $F_{z}$ (unit: $\mathrm{N}$ ). As force of interest is $F_{\theta}$, relationship between $F_{z}$ and $F_{\theta}$ can be calculated as Equation (1).

$$
F_{\theta}=F_{z} \cos \theta
$$

During the scotch tape test, the angle $\left(90^{\circ}-\theta\right)$ was changed from $60^{\circ}$ to $90^{\circ}$; thus, $F_{\theta}=0.5 F_{z}$ at $45^{\circ}$, and $F_{\theta}=F_{z}$ at $90^{\circ}$. For simplicity, we used the measured $F_{z}$ from the scotch tape test to extract the adhesion strength.

Metal adhesion to parylene substrate was then measured with the scotch tape test. Scotch tape was attached to the parylene surface, slightly away from the left-end metal line to the right-end of the metal. After that, two different strokes $(10 \mathrm{~mm} / \mathrm{min}$ and $1 \mathrm{~mm} / \mathrm{min})$ were applied to the scotch tape, and corresponding force was measured as shown in Figure 6. All metal lines were debonded from the parylene substrate for all the cases. It was found that the sample with $\mathrm{CF}_{4}$ treatment needs more force than that without $\mathrm{CF}_{4}$ treatment, which means a parylene surface with $\mathrm{CF}_{4}$ treatment sticks better to scotch tape. This is a proof that parylene surface energy can be increased with only $\mathrm{CF}_{4}$ treatment without $\mathrm{O}_{2}$.

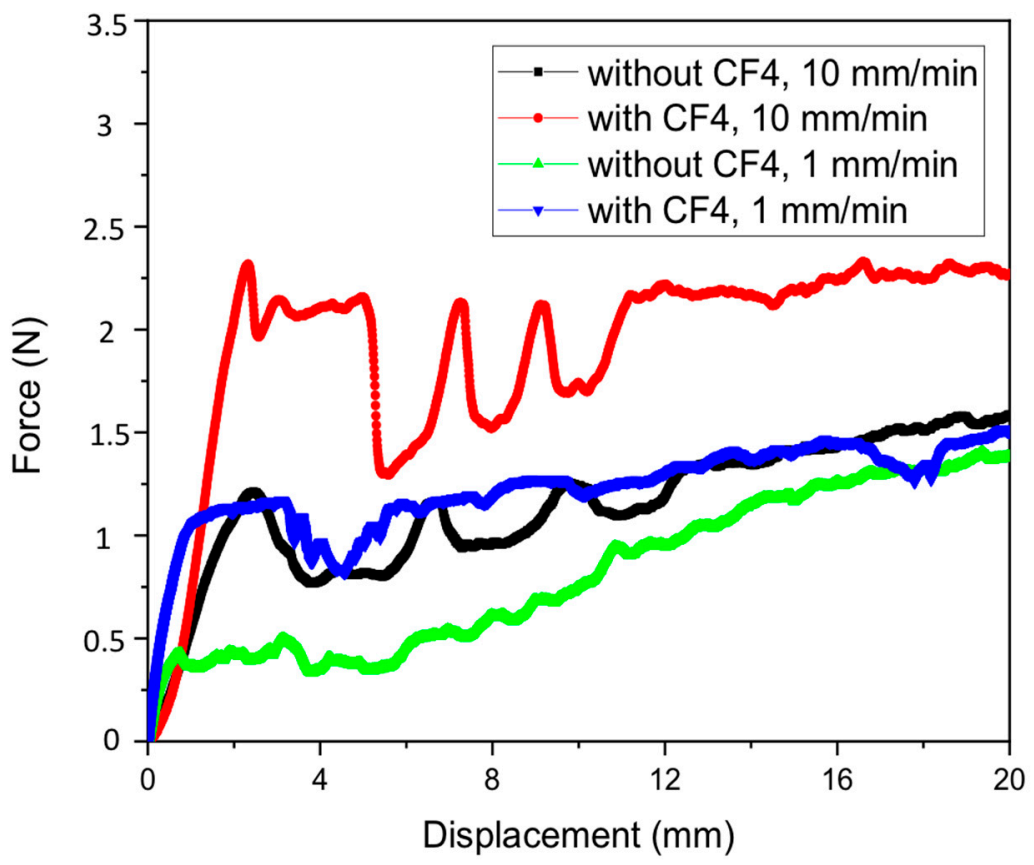

Figure 6. Force-displacement curves from scotch tape test with metal lines on parylene substrate.

The first peak in each measured force was due to initiation of metal debonding, which makes abrupt drop of force. Minimal adhesion force is found when a stroke of $1 \mathrm{~mm} / \mathrm{min}$ was applied to the parylene test sample without $\mathrm{CF}_{4}$ treatment (green line). It can be said that the metal adhesion had lower than the adhesion value estimated from the first peak. The adhesion can be calculated as follows; $(0.5 \mathrm{~N} / 12 \mathrm{~mm}) \times(1.2 \mathrm{~mm} / 12 \mathrm{~mm})=4.2 \mathrm{~N} / \mathrm{m}$. As all metal lines were debonded, the metal adhesion should have had lower than $4.2 \mathrm{~J} / \mathrm{m}^{2}$. Thus, a lower stoke of $0.1 \mathrm{~mm} / \mathrm{min}$ was applied to find metal adhesion to the parylene substrate. In this case, the scotch tape was attached only to the narrow metal lines of $\mathrm{CF}_{4}$ treated parylene and then force was recoded while stroke of $0.1 \mathrm{~mm} / \mathrm{min}$ is applied. The measured force-displacement curve was compared with the previous results of $1 \mathrm{~mm} / \mathrm{min}$ and $10 \mathrm{~mm} / \mathrm{min}$, as shown in Figure 7. As remarked in Figure 7, the scotch tape was debonded up to $0.9 \mathrm{~N}$ without metal line delamination, and one metal line started to debond from $0.91 \mathrm{~N}$. Therefore, metal adhesion could be extracted from this peak force; $(0.91 \mathrm{~N} / 12 \mathrm{~mm}) \times(0.2 \mathrm{~mm} / 12 \mathrm{~mm})=(76 \mathrm{~N} / \mathrm{m}) \times$ 
$(0.017)=1.29 \mathrm{~N} / \mathrm{m}=1.29 \mathrm{~J} / \mathrm{m}^{2}$. Note that inset shows transferred metal lines on the scotch tape. Scotch tape strokes of $1 \mathrm{~mm} / \mathrm{min}$ and $10 \mathrm{~mm} / \mathrm{min}$ introduced large force fluctuation, which would result from relatively large applied force compared with interfacial energy.

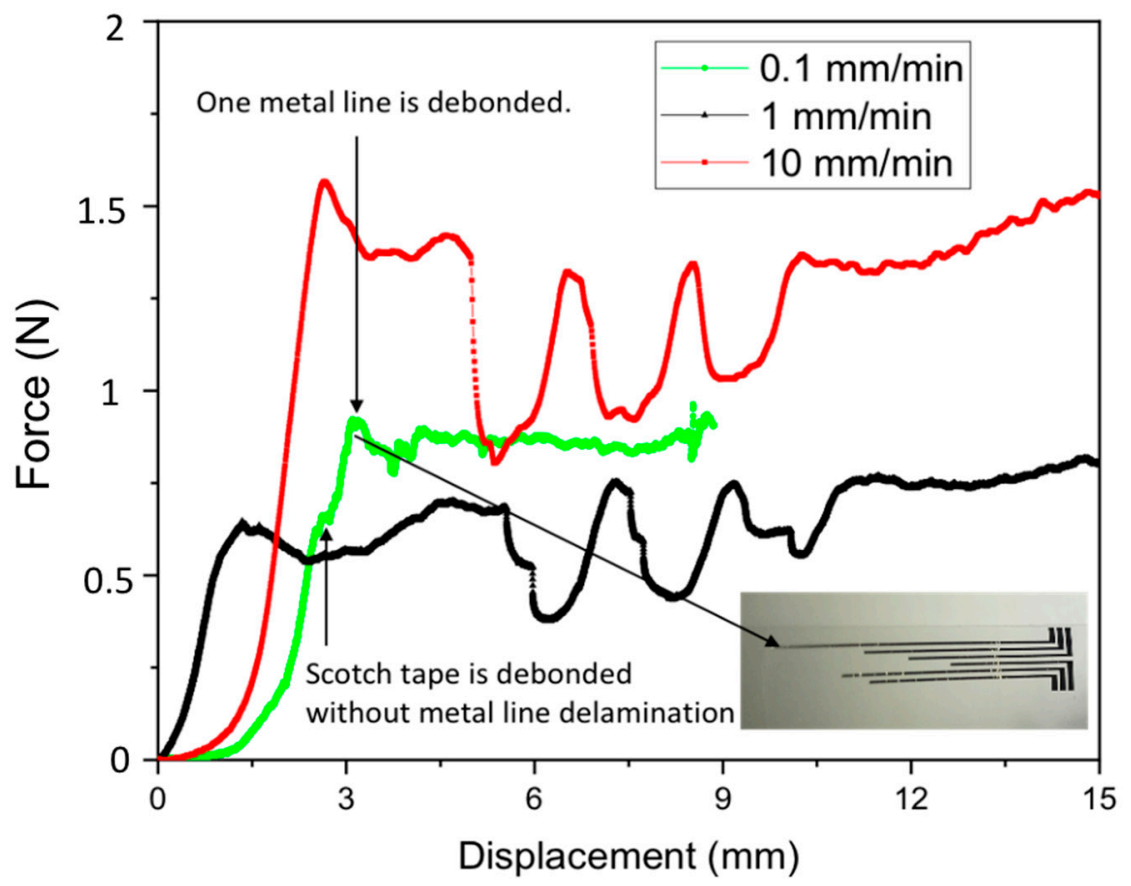

Figure 7. Force-displacement curves from scotch tape test with metal lines on parylene substrate with $\mathrm{CF}_{4}$ treatment.

Table 2 summarizes adhesion force between parylene and metal layer of previous reports compared with this work. The majority of the studies on metal-parylene adhesion force deal with parylene layer deposited on metal film with inteface treatment. Thus, they can provide from tens N/m to hundreds $\mathrm{N} / \mathrm{m}$ of adhesion force. A thin metal layer, like Al thin film, on PET(Polyethylene terephthalate) layer has $46.7 \mathrm{~N} / \mathrm{m}$ of adhesion. The thin gold metal line of this work had $1.29 \mathrm{~N} / \mathrm{m}$ of adhesion force, which may result from the relatively narrow metal line of $200 \mu \mathrm{m}$.

Table 2. Comparison of other research results with scotch tape test.

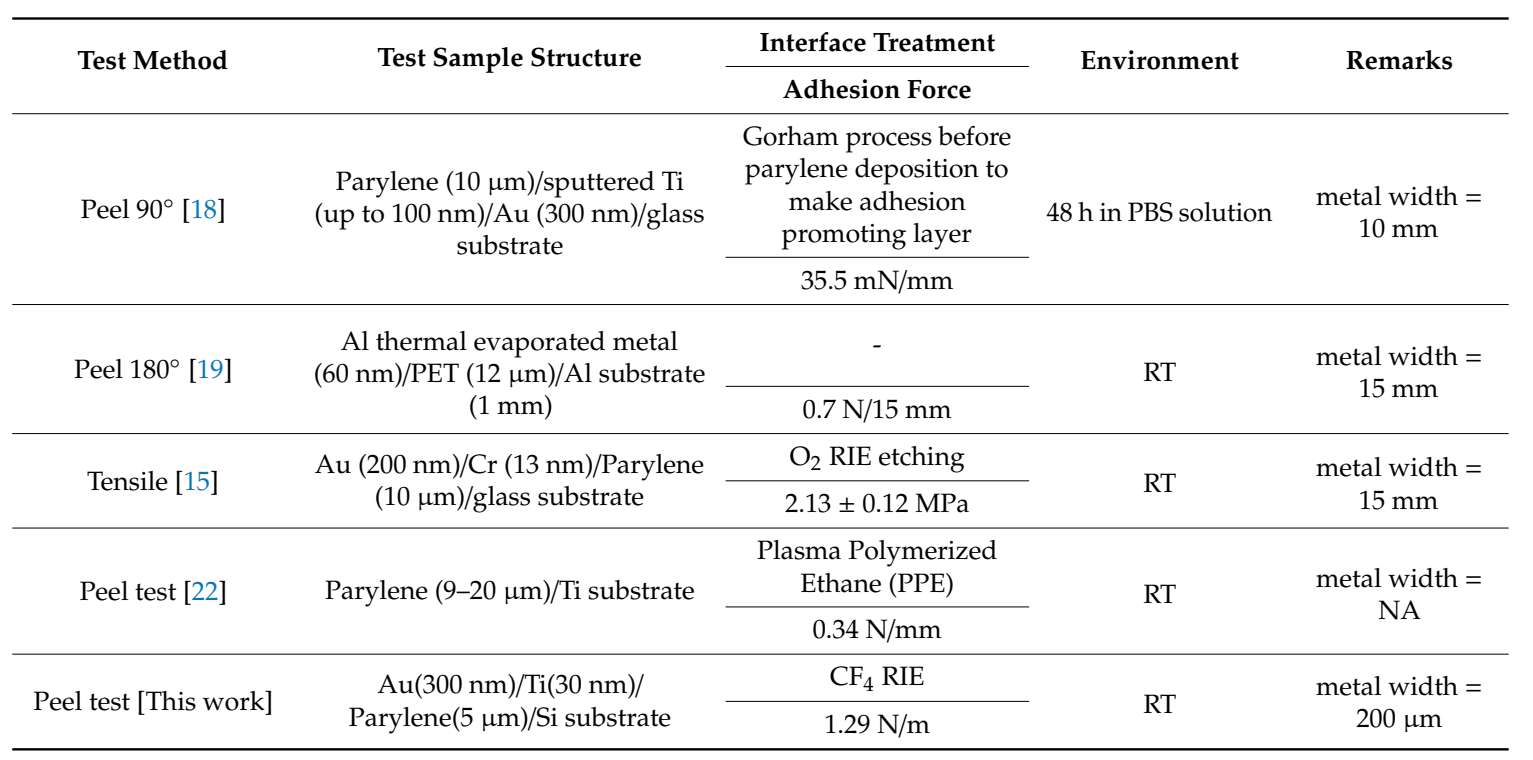




\section{FEM Modeling and Simulation}

FEM modeling and simulation is very useful to understand stress effect and corresponding deformation of MEMS package, debonding characteristics of a transfer packaging, and mechanical behaviors related with delamination [23-27]. Especially, debonding of a substrate and film delamination can be studied by adopting a CZM (Cohesive Zone model) to represent the interface of interest [28-30].

For FEM modeling, material properties of each element are important to get good simulation results. Required material properties in this modeling are Young's moduli and poisson ratios of scotch tape and parylene and strain energy release rate of interface between the scotch tape and parylene. Young's modulus of the scotch tape is extracted from tensile test result, as shown in Figure 8 . The Young's modulus of the scotch tape is $6.9 \mathrm{MPa}$ in the elastic region, and the maximum applied force in the elastic region is $7.6 \mathrm{~N}$ when the applied strain is $2.2 \%(2.2 \mathrm{~mm}$ elongation as test scotch tape length is $100 \mathrm{~mm}$ ). From the tensile test result, scotch tape in the metal adhesion test would be in the elastic region as the applied force is less than $2 \mathrm{~N}$ in all the cases. Poisson ratio of the scotch tape is assumed to be 0.4 as other polymer materials. Young's modulus and poisson ratio of parylene are $2.67 \mathrm{GPa}$, as extracted in previous work, and 0.4, respectively [23]. Table 3 summarizes material properties for the FEM model. Note that interface material properties were defined with critical strain energy release rate. The value for critical strain energy release rate was the measured adhesion force as explained earlier.

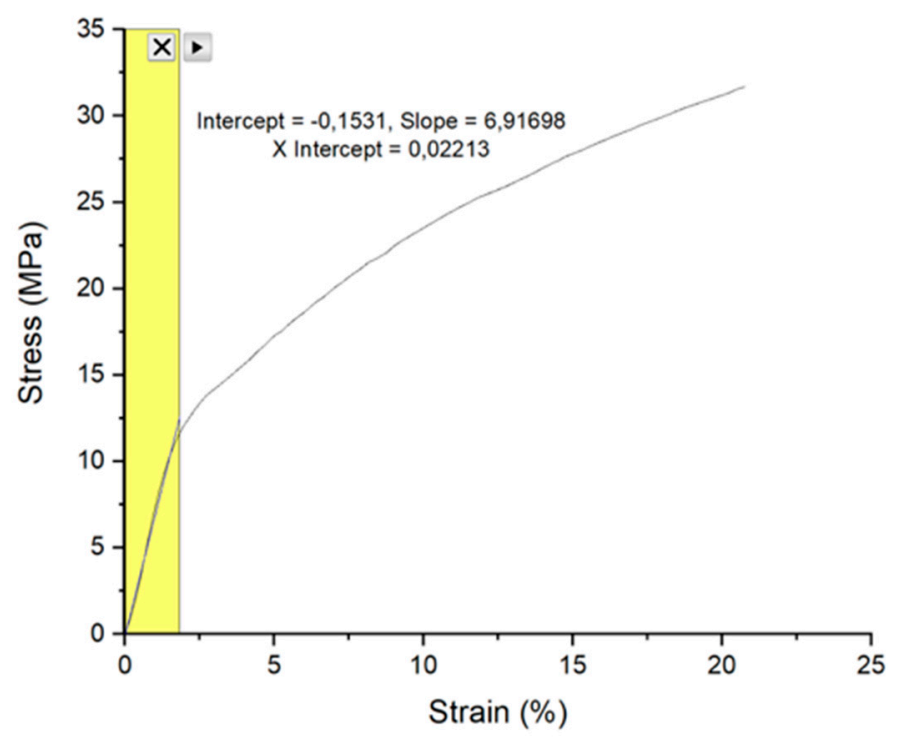

Figure 8. Tensile test result of scotch tape.

Table 3. Material properties of materials and interface.

\begin{tabular}{ccc}
\hline Material Properties & Scotch Tape & Parylene \\
\hline Young's modulus $(\mathrm{Pa})$ & $6.9 \times 10^{6}$ & $2.7 \times 10^{9}$ \\
Poisson ratio & 0.4 & 0.4 \\
- & \multicolumn{2}{c}{ Interface } \\
$\quad$ Critical mode I & \multicolumn{2}{c}{1.3} \\
$\begin{array}{c}\text { energy release rate }\left(\mathrm{J} / \mathrm{m}^{2}\right) \\
\text { Critical mode II }\end{array}$ & \multicolumn{2}{c}{1.3} \\
$\begin{array}{c}\text { energy release rate }\left(\mathrm{J} / \mathrm{m}^{2}\right) \\
\text { Critical mode III } \\
\text { energy release rate }\left(\mathrm{J} / \mathrm{m}^{2}\right)\end{array}$ & \multicolumn{2}{c}{1.3} \\
\hline
\end{tabular}


Given with material properties, modeling and simulation of the scotch tape test was performed in two steps: 1) crack propagation behavior of the interface between the scotch tape and parylene substrate 2) debonding of the scotch tape from parylene substrate based on CZM.

A 2D FEM model for crack propagation was built, as shown in Figure 9a. The length of this model was $1000 \mu \mathrm{m}$, and thickness was $50 \mu \mathrm{m}$ for scotch tape and $5 \mu \mathrm{m}$ for parylene polymer. The following boundary conditions were applied: bottom line is fixed and displacement load is applied to left-top end, having $50 \mu \mathrm{m}$ width. Note that 2D model behavior was defined as plane strain. Total deformation of the model when displacement of $100 \mu \mathrm{m}$ in y direction was applied to the scotch tape is presented in Figure $9 \mathrm{~b}$. As is in the scotch tape test, delamination of the interface between scotch tape and parylene occurred, and crack propagated in x-direction.

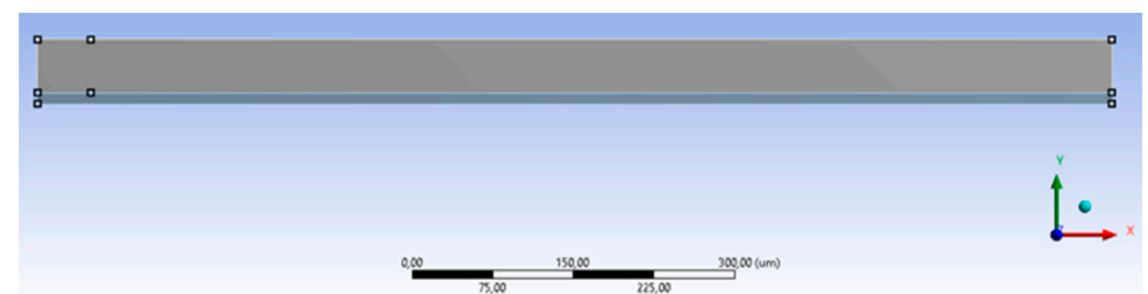

(a) 2D FEM model for scotch tape test

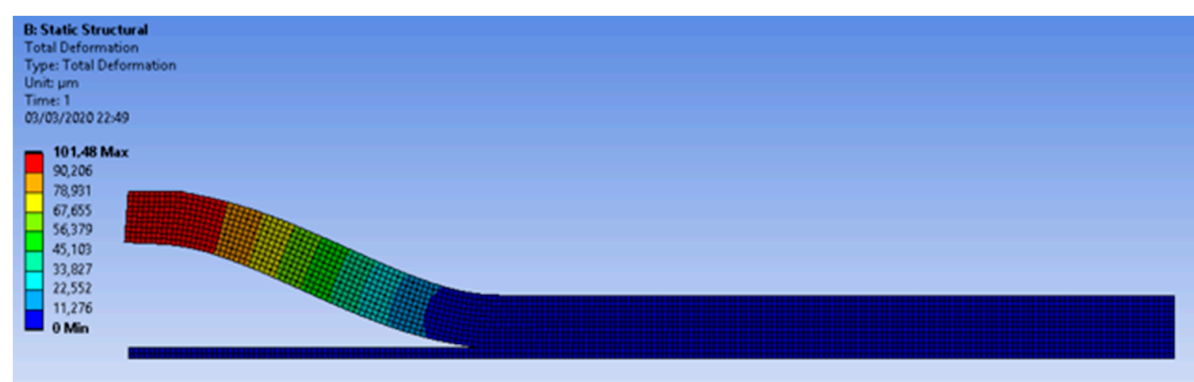

(b) Total deformation

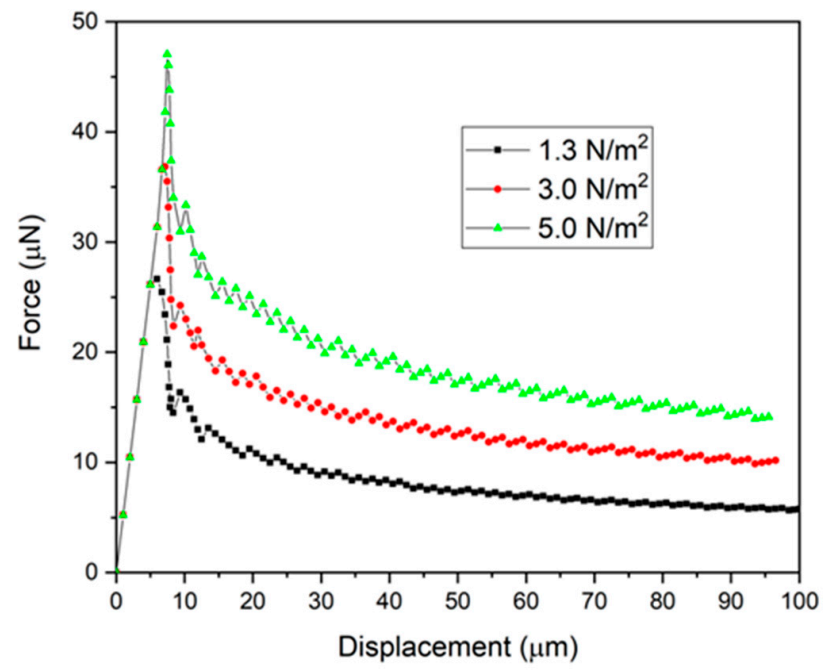

(c) Force-Displacement curves as function of interface energy

Figure 9. Crack propagation model and simulation results.

Force-displacement was investigated as function of interface adhesion energy, as shown in Figure 9c. The required force for crack initiation was increased as interface adhesion energy increased, as expected. The force magnitude smaller than the measurement would have been due to thickness effect 
in 2D simulation. An important parameter in this graph is minimal displacements for crack initiation: $5 \mu \mathrm{m}, 6.7 \mu \mathrm{m}$, and $7.6 \mu \mathrm{m}$ for $1.3 \mathrm{~N} / \mathrm{m}^{2}, 3.0 \mathrm{~N} / \mathrm{m}^{2}$, and $5.0 \mathrm{~N} / \mathrm{m}^{2}$, respectively. These parameters are included in the following 3D interface delamination as a part of CZM parameters. From the simulation results, strain energy release rate (SERR) for mode 1 referring to VCCT (Virtual Crack Closure Technique) (G1), SERR for mode 2 from VCCT (G2), and SERR for mode 3 from VCCT (G3) were found $0.5 \mathrm{~J} / \mathrm{m}^{2}, 0.75 \mathrm{~J} / \mathrm{m}^{2}$ and $0 \mathrm{~J} / \mathrm{m}^{2}$, respectively. The total amount of VCCTs corresponded to the interface energy of $1.3 \mathrm{~N} / \mathrm{m}^{2}$. Principal modes of the fracture of the delamination was from mode 1 and mode 2.

Figure 10a shows 3D model for the CZM interface delamination. As indicated in Figure 10b, there were two different regions in this model: pre-cracked (interface I) and CZM-modeled (interface II). CZM is a useful way to simulate interface delamination, which is frequently used for thin film delamination and transfer packaging technique [24,25]. The interface II, which is of interest for the adhesion, is modeled with CZM (Cohesive Zone Model) parameters, as explained in Figure 10c. As the bilinear CZM model needs at least two parameters, maximum normal traction and normal displacement at debonding was defined, as presented in Table 4 . The minimal gaps for the fracture initiation found from the previous crack propagation simulation were included for 3D CZM simulation to estimate applied force to initiate the interface crack.

Table 4. Cohesive Zone model (CZM) parameters.

\begin{tabular}{ll}
\hline Parameter Name & Value \\
\hline Maximum normal traction & $0.5 \mathrm{MPa}$ \\
Normal displacement jump at completion of debonding & $5 \mu \mathrm{m}$ \\
Maximum tangential traction & $0.5 \mathrm{MPa}$ \\
Tangential displacement jump at completion of debonding & $5 \mu \mathrm{m}$ \\
\hline
\end{tabular}

A displacement load was applied to one-end of the scotch tape, and then the force-displacement was extracted from the simulation. Referring to bilinear CZM model, critical strain energy release rate was calculated $1.25 \mathrm{~J} / \mathrm{m}^{2}$. Initial width of the 3D model was $200 \mu \mathrm{m}$ as was the fabricated metal electrode width. As in the 2D case, displacement load was applied to left-tip end. Extracted force-displacement curve at the loading place is presented in Figure 11. Minimal force for debonding of scotch tape was estimated $1.2 \mathrm{~N} / \mathrm{m}$, while measured one was $1.29 \mathrm{~N} / \mathrm{m}$. Adhesion force of the simulation had a good agreement with the measurement. Width of metal electrode could have been increased to get larger interface adhesion, as shown in Figure 11 When wider metal electrode is used to achieve larger metal-parylene adhesion, metal line impedance for neural signal acquisition should be taken into account.

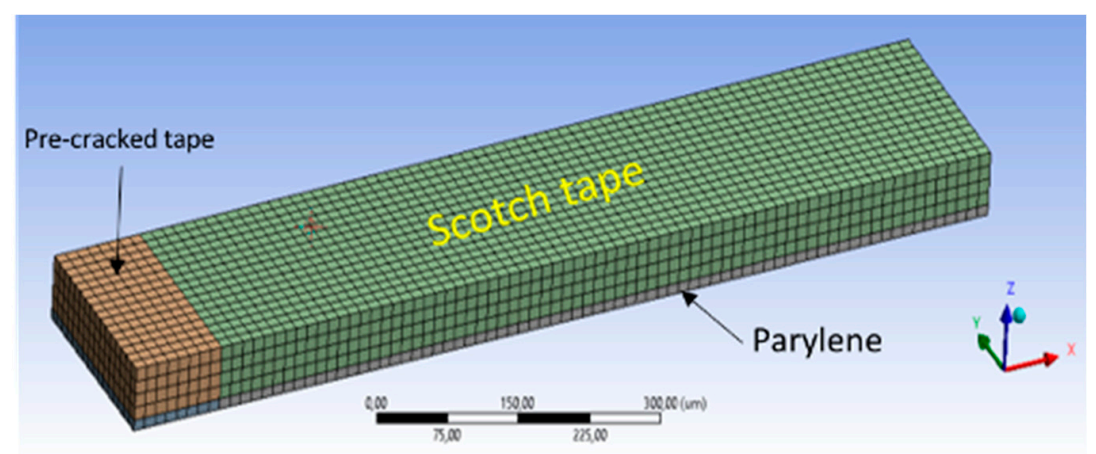

(a) 3D view

Figure 10. Cont. 
Load

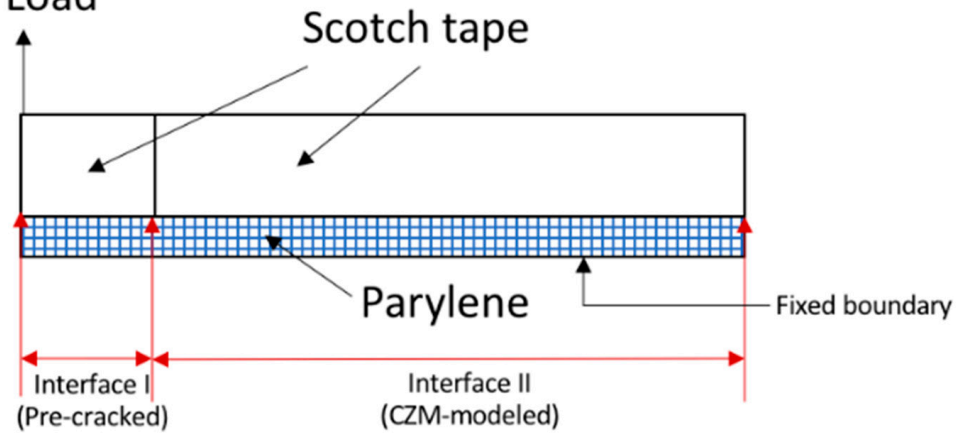

(b) Side view

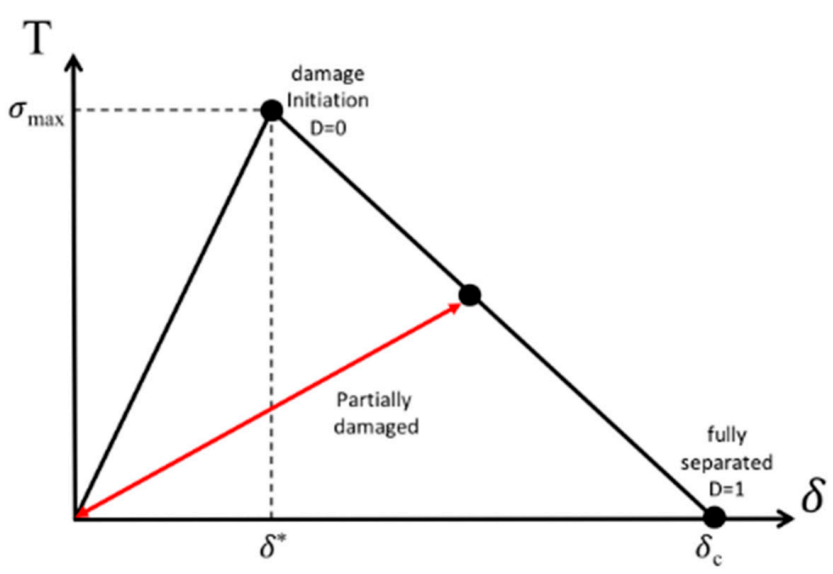

Tmax $=$ maximum normal cohesive traction $(\sigma \max )$

$\delta^{*}=$ normal displacement jump at maximum normal cohesive traction

$\delta \mathrm{c}=$ normal displacement jump at the completion of debonding

(c) Bilinear CZM model parameters

Figure 10. Three-dimensional Finite Element Method (FEM) model for Cohesive Zone model (CZM) interface delamination.

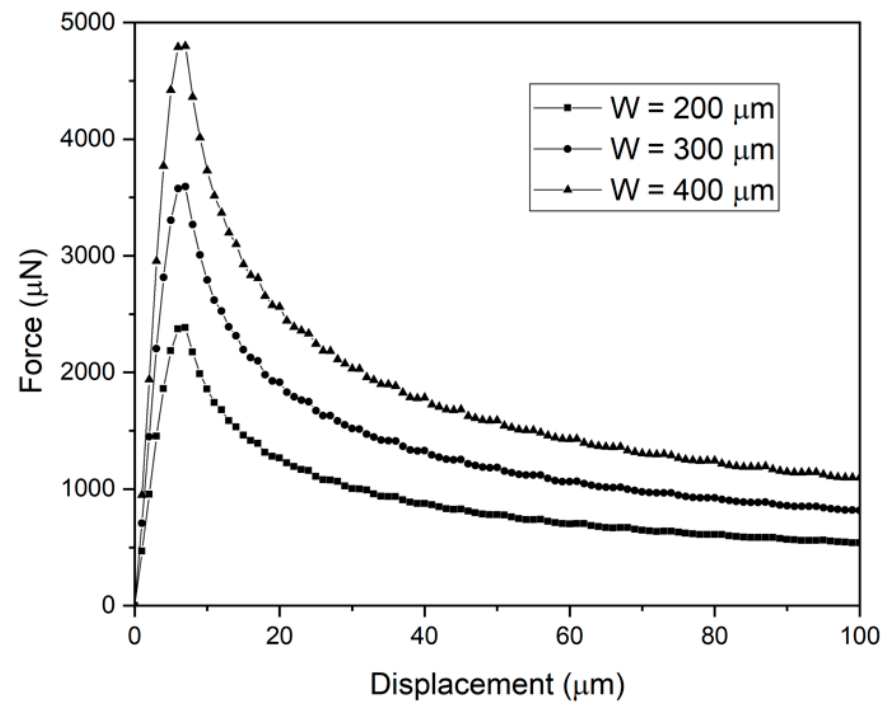

Figure 11. Force-displacement curves as function of metal width. 


\section{Conclusions}

Thin film flexible polymeric devices, such as a parylene-metal-parylene system, are being used for measuring nerve impulse from the central or peripheral nerve systems. Such thin-film polymeric devices provide advantages of flexibility and biocompatibility, but they are prone to delamination and carry concerns about their mechanical robustness. Therefore, metal adhesion strength to polymer substrate is important. The adhesion of metal electrodes to parylene substrate was measured by the scotch tape test. Thin and long metal electrodes was patterned on a parylene substrate in which the surface was modified by $\mathrm{CF}_{4}$ plasma etch before the metal deposition through e-beam evaporation. Metal adhesion strength was estimated by measuring force-displacement curve of the scotch tape test. The estimated metal adhesion was $1.3 \mathrm{~J} / \mathrm{m}^{2}$. Experiment result was verified through FEM modeling of the scotch tape test. The proposed modeling method provided adhesion force having good agreement with experimental result. Although a thin-film parylene-based device can provide excellent short-term reliability, there exists one significant drawback of poor adhesion to metallic layer. The failure of the metal electrode on the parylene substrate is accelerated in the wet environment of a human body and under mechanical forces originating from body movement. Therefore, mechanical integrity in conditions of a human body implant or movement will be performed to assess long-term reliability of the parylene-metal devices, along with the biocompatibility of the parylene-base neural probe.

Author Contributions: Conceptualization, S.S. and J.K.; methodology, H.P.; software, H.P.; validation, S.S., H.P. and J.K.; formal analysis, S.S.; investigation, H.P.; resources, H.P.; data curation, H.P.; writing-original draft preparation, S.S.; writing — review and editing, S.S.; visualization, S.S.; supervision, J.K.; project administration, J.K.; funding acquisition, J.K. All authors have read and agreed to the published version of the manuscript.

Funding: This research was supported by the convergence technology development program for bionic arm through the National Research Foundation of Korea (NRF) funded by the Ministry of Science \& ICT (No. 2017M3C1B2085292). This work was also supported by the Korea Institute of Science and Technology institutional program (2E30090 and 2V08590).

Conflicts of Interest: The authors declare no conflict of interest.

\section{References}

1. Anderson, D.J.; Najafi, K.; Tanghe, S.J.; Evans, D.A.; Levy, K.L.; Hetke, J.F.; Xue, X.; Zappia, J.J.; Wise, K.D. Batch-fabricated thin-film electrodes for stimulation of the central auditory system. IEEE Trans. Biomed. Eng. 1989, 36, 693-704. [CrossRef] [PubMed]

2. Campbell, P.K.; Normann, R.A.; Horch, K.W.; Stensaas, S.S. A chronic intracortical electrode array: Preliminary results. J. Biomed. Mater. Res. Appl. Biomat. 1989, 23, 245-259.

3. Eichenbaum, H.; Kuperstein, M. Extracellular neural recording with multichannel microelectrodes. J. Electrophysiol. Tech. 1986, 13, 189-209.

4. Najafi, K.; Ji, J.; Wise, K.D. Scaling limitation on silicon multichannel recoding probe. IEEE Trans. Biomed. Eng. 1990, 37, 1-11. [CrossRef]

5. Campbell, P.K.; Jones, K.E.; Huber, R.J.; Horch, K.W.; Normann, R.A. A silicon-based, three-dimensional neural interface: Manufacturing processes for an intracortical electrode array. IEEE Trans. Biomed. Eng. 1991, 38, 758-768. [CrossRef]

6. Takeuchi, S.; Suzuki, T.; Mabuchi, K.; Fujita, H. 3D flexible multichannel neural probe array. J. Micromechanics Microengineering 2004, 14, 104-107. [CrossRef]

7. Kim, O.; Choi, W.; Jung, W.; Jung, S.; Park, H.; Park, J.W.; Kim, J. Novel Neural Interface Electrode Array for the Peripheral Nerve. In Proceedings of the International Conference on Rehabilitation Robotics (ICORR), London, UK, 17-20 July 2017.

8. Castagnola, V.; Descamps, E.; Lecestre, A.; Dahan, L.; Remaud, J.; Nowak, L.G.; Bergaud, C. Parylene-based flexible neural probes with PEDOT coated surface for brain stimulation and recording. Biosens. Bioelectron. 2015, 67, 450-457. [CrossRef]

9. Cheung, K.C.; Renaud, P.; Tanila, H.; Djupsund, K. Flexible Polyimide Microelectrode Array for in Vivo Recordings and Current Source Density Analysis. Biosens. Bioelectron. 2007, 22, 1783-1790. [CrossRef] 
10. Stieglitz, T. Development of a micromachined epiretinal vision prosthesis. J. Neural Eng. 2009, 6, 065005. [CrossRef]

11. Ordonez, J.; Schuettler, M.; Boehler, C.; Boretius, T.; Stieglitz, T. Thin films and microelectrode arrays for neuroprosthetics. MRS Bull. 2012, 37, 590-598. [CrossRef]

12. Chen, Z.; Ryzhik, L.; Palanker, D. Current Distribution on Capacitive Electrode-Electrolyte Interfaces. Phys. Rev. Appl. 2020, 13. [CrossRef]

13. Onzález, C.; Rodríguez, M. A flexible perforated microelectrode array probe for action potential recording in nerve and muscle tissues. J. Neurosci. Methods 1997, 72, 189-195. [CrossRef]

14. Lee, C.D.; Meng, E. Mechanical properties of thin-film Parylene- metal-Parylen devices. Front. Mech. Eng. 2015, 1, 10. [CrossRef]

15. Xie, Y.; Pei, W.; Guo, D.; Zhang, L.; Zhang, H.; Guo, X.; Xing, X.; Yang, X.; Wang, F.; Gui, Q.; et al. Improving adhesion strength between layers of an implantable parylene-C electrode. Sens. Actuators A Phys. 2017, 260, 117-123. [CrossRef]

16. Oliva, N.; Mueller, M.; Stieglitz, T.; Navarro, X.; del Valle, J. On the use of Parylene C polymer as substrate for periphral nerve electrode. Sci. Rep. 2018, 8, 1-12.

17. Chang, J.H.; Lu, B.; Tai, Y.C. Adhesion-enhancing surface treatments for parylene deposition. In Proceedings of the International Solid-State Sensors, Actuators and Microsystems Conference (Transducers 2011), Beijing, China, 5-9 June 2011.

18. Jesdinszki, M.; Struller, C.; Rodler, N.; Blondin, D.; Cassio, V.; Kucukpinar, E.; Langowski, H.-C. Evaluation of Adhesion Strength Between Thin Aluminum Layer and Poly(ethylene terephthalate) Substrate by Peel Tests-A Practical Approach for the Packaging Industry. J. Adhes. Sci. Technol. 2012, 26, 2357-2380. [CrossRef]

19. Tsai, L.-C.; Rezaee, M.; Haider, M.I.; Yazdi, A.; Salowitz, N.P. QUANTITATIVE MEASUREMENT OF THIN FILM ADHESION FORCE. In Proceedings of the ASME 2019 Conference on Smart Materials, Adaptive Structures and Intelligent Systems SMASIS 2019, Louisville, KY, USA, 9-11 September 2019.

20. Min, K.; Rammohan, A.R.; Lee, H.S.; Shin, J.; Lee, S.H.; Goyal, S.; Park, H.; Mauro, J.C.; Stewart, R.; Botu, V.; et al. Computational approaches for investigating interfacial adhesion phenomena of polyimide on silica glass. Sci. Rep. 2017, 7, 10475. [CrossRef]

21. ASTM-D-3359. Standard Test Methods for Measuring Adhesion by Tape Test; ASTM International: West Conshohocken, PA, USA, 2010.

22. Yamagishi, F.G. Investigations of plasma-polymerized films as primers for Parylene-C coatings on neural prosthesis materials. Thin Solid Film. 1991, 202, 39-50. [CrossRef]

23. Seok, S.; Park, H.D.; Choi, W.; Kim, O.; Kim, J. Analysis of Thin Film Parylene-Metal-Parylene Device Based on Mechanical Tensile Strength Measurement. In Proceedings of the DTIP 2019, Berlin, Germany, 8-12 September 2019.

24. Lishchynska, M.; O’Mahony, C.; Slattery, O.; Wittler, O.; Walter, H. Evaluation of Packaging Effect on MEMS Performance: Simulation and Experimental Study. IEEE Trans. Adv. Packag. 2007, 30, 629-635. [CrossRef]

25. Seok, S.; Rolland, N.; Rolland, P.-A. A Theoretical and Experimental Study of BCB Thin-Film Cap Zero-Level Package Based on FEM Simulations. J. Micromechanics Microengineering 2010. [CrossRef]

26. Seok, S. A Theoretical Study on Post-it-like Debonding Process for BCB Cap Transfer Packaging Based on FEM Simulation. IEEE Trans. Compon. Packag. Manuf. Technol. CPMT 2015, 5, 1417-1422. [CrossRef]

27. Seok, S. Fabrication and Modeling of Nitride Thin Film Encapsulation Based on Anti-Adhesion-Assisted Transfer Technique and Nitride/BCB Bilayer Wrinkling. IEEE Trans. Compon. Packag. Manuf. Technol. CPMT 2016, 6, 1301-1307. [CrossRef]

28. Yan, Y.; Shang, F. Cohesive zone modeling of interfacial delamination in PZT thin films. Int. J. Solids Struct. 2009, 46, 2739-2749. [CrossRef]

29. Samimi, M.; van Dommelen, J.A.W.; Geers, M.G.D. A three-dimensional self-adaptive cohesive zone model for interfacial delamination. Comput. Methods Appl. Mech. Eng. 2011, 200, 3540-3553. [CrossRef]

30. Moslemi, M.; Khoshravan, M. Cohesive Zone Parameters Selection for Mode-I Prediction of Interfacial Delamination. J. Mech. Eng. 2015, 61, 507-516. [CrossRef]

(C) 2020 by the authors. Licensee MDPI, Basel, Switzerland. This article is an open access article distributed under the terms and conditions of the Creative Commons Attribution (CC BY) license (http://creativecommons.org/licenses/by/4.0/). 